Classification

Physics Abstracts

$42.30-81.70 . \mathrm{C}$

\title{
3D Imaging Applications at the LISA Laboratory during the Last Ten Years
}

\author{
Michel Jourlin $\left({ }^{1}\right)$, Cédric Bertrand $\left({ }^{2}\right)$, Jean-Loup Coudert $\left({ }^{3,1}\right)$, Freddy Darsonville $\left({ }^{1}\right)$, \\ Philippe Gremillet $\left({ }^{4}\right)$, Sandrine Martinez $\left({ }^{1}\right)$, Jean-Charles Pinoli $\left({ }^{5,1}\right)$, Chantal Revol $\left({ }^{1}\right)$ \\ and Frédéric Trunde $\left({ }^{1}\right)$ \\ $\left({ }^{1}\right)$ Laboratoire Image, Signal et Acoustique, CNRS EP0092, École Supérieure de Chimie, \\ Physique et Électronique de Lyon, 43 boulevard du 11 Novembre 1918, BP 2077, \\ 69616 Villeurbanne Cedex, France \\ $\left({ }^{2}\right)$ LOREAL, Laboratoire de Recherche Avancée, 1 avenue Eugène Schueller, \\ 93600 Aulnay-sous-Bois, France \\ $\left({ }^{3}\right)$ Faculté d’Odontologie de Lyon, rue Guillaume Paradin, 69372 Lyon Cedex 08, France \\ $\left({ }^{4}\right)$ MISIS, 10D rue de la Productique, 42000 Saint-Étienne, France \\ $\left({ }^{5}\right)$ Pechiney, Centre de Recherches, Parc Economique Centr'Alp, 38340 Voreppe, France
}

Résumé. - Cet article a pour ambition d'illustrer à la fois les formidables potentialités ouvertes dans l'étude tri-dimensionnelle d'objets ou de structures (matériaux, organes...) par les technologies récentes d'imagerie microscopique (électronique, optique confocale, à force atomique...) qui donnent accès à des informations tant surfaciques que volumiques, et la nécessité de créer des outils et modèles complexes indispensables pour exploiter les informations fournies par ces capteurs, tant au niveau mathématique (modélisation, interpolation, corrélation, reconstruction...), qu'informatique (facettisation, lissage, visualisation... mais aussi structures de données adaptées au stockage et à l'utilisation de fichiers volumineux, architectures parallèles...). C'est sur la création, le développement et la mise en oeuvre de ces outils théoriques et pratiques qu'ont porté les contributions originales du Laboratoire LISA depuis dix ans dans le domaine de l'imagerie 3D. Cet article a pour propos de présenter brièvement des travaux d'analyse d'image réalisés au Laboratoire LISA et surtout d'illustrer les principales réussites applicatives par des images. Les exemples présentés concernent le domaine biomédical (cellules biologiques, cheveux, machoires, épidermes in-vivo) et celui des matériaux (textiles, bétons, alliages d'aluminium).

Abstract. - This article ambitiously aims at illustrating the tremendous potentialities offered by new imaging technologies (electron microscopy, confocal microscopy and atomic force microscopy...), that give access to either volumic or surfacic informations, and the necessity to create high-level tools and models that are essential for the treatment of the information provided by the sensors, as well from a mathematical point of view (modeling, interpolation, correlation, reconstruction...) as under the computing aspect (facettisation, smoothing, visualization... but also data structures adapted to the storage and use of voluminous files, parallel architectures...). Since ten years the LISA Laboratory has focused in the field of 3D imaging on the creation, development and implementation of such theoretical and practical tools. This article briefly presents the main works on image analysis at LISA Laboratory and especially illustrates by images the main successfully addressed three dimensional imaging applications. The overviewed examples concern the biomedical domain (biological cells, hairs, jaws, epidermis) and that of materials (textiles, concretes, aluminium alloys). 


\section{Introduction}

The LISA Laboratory regroups a wide range of apparata and human skills for performing researches in the field of image and signal processing from both theoretical and practical viewpoints. The LISA's specificity lies in the multidisciplinarity of its staff of researchers (mathematicians, physicists, computer scientists and engineers, electronics engineers) that allows to cover both the abstract level aspects (modeling, representation) and to achieve concrete realizations (electronic boards and circuits, specific softwares).

During the last ten years the LISA's research activities have been partly focused on threedimensional (3D) image processing, since this recent research area requires specific models and treatments together with powerful computing and electronics tools. The LISA Laboratory introduced and developed novel ideas and concepts directly or indirectly useful for 3D image processing purpose, mainly in the field of mathematical and computational imaging. They will be partly referenced at particular text points in this article.

Most part of these works were performed in collaboration with scientists and engineers of various organizations and companies (Institute of Immunology and Virology of Zürich, Faculty of Dentistry of Lyon, L'OREAL Company Advanced Research Center, French High School for State Public Works, French Textile Institute, Pechiney Corporate Research Center...).

The application examples briefly overviewed in this article have been selected to illustrate the LISA's methodological approach which is going from the theoretical level down to real applications. The present article highlights the practical aspects by means of a lot of significative images, rather than the scientific and technical developments. References of the related published or submitted proceedings and journal articles are given for more interested readers.

\section{3D Imaging Application Examples in the Biomedical Domain}

Historically, the first research works of the LISA Laboratory in the field of 3D imaging started at the end of the 80's. The first addressed application area was the biomedical domain.

2.1 Biomedical Cells. - In collaboration with the Institute of Immunology and Virology of Zürich (Switzerland), the LISA Laboratory has developed during the 1986-1989 years an original method for complete 3D imaging of Merkel cells (rare cells of the human epidermis) at a $40 \mathrm{~nm}$ resolution from serial sections acquired by transmission electron microscopy [1]. The novelties were as well in the cells preparation and cutting procedure as in $3 \mathrm{D}$ image reconstruction and visualization [2]. They largely involved non-linear algorithms based on the logarithmic image processing approach [3,4]. In 1989-1990, the use of a scanning transmission electron microscope allowed images with high contrast and better resolution [5].

A further application example within the biomedical domain was the $3 \mathrm{D}$ imaging of HIVinfected entire cells [6] by scanning transmission electron microscopy at a $15 \mathrm{~nm}$ calculated resolution. A new method to generate linked triangles as a representation of the surface cells was reported, as well a visualization process mixing image synthesis and grey-level information (Fig. 1).

2.2 HUMAN HAIRS. - In collaboration with the LOREAL Company Advanced Research Laboratory, the 3D image reconstruction and visualization of human hairs by confocal optical microscopy has been reported in 1993 [7]. Freshly plucked hair and eyelash were collected and prepared at the time of experiment. Confocal microscopy provided high resolution images (about $0.25 \mu \mathrm{m}$ ) with no out-of-focus areas (Fig. 2). The extracted 3D information was used to describe the hair structure and to characterize the effects of hair treatments on the cuticle. 


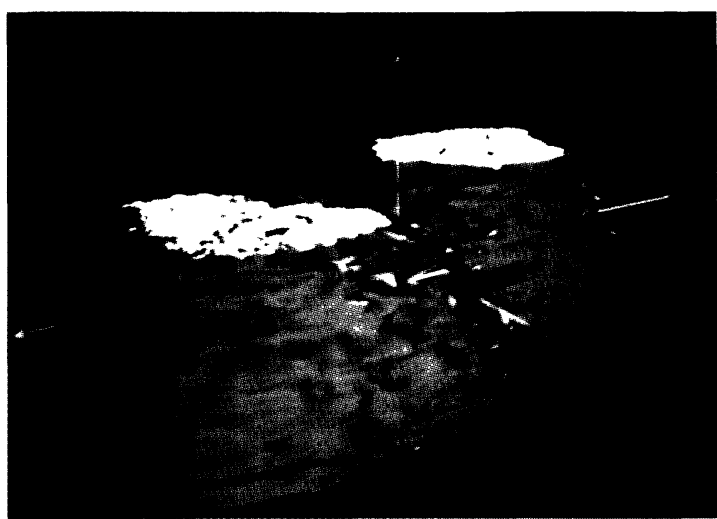

Fig. 1.

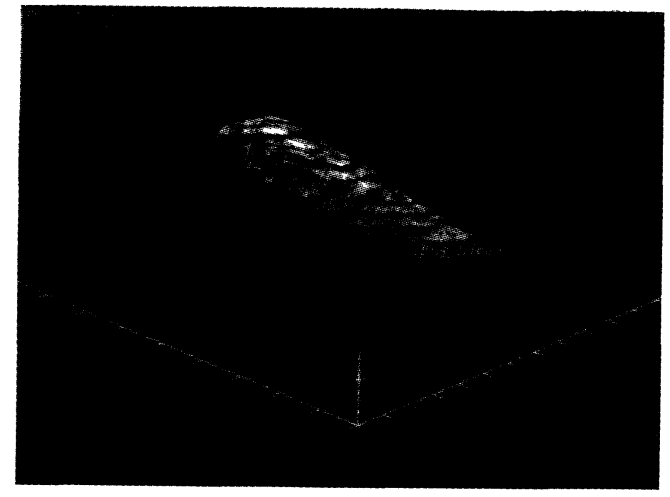

Fig. 2.

Fig. 1. - View of two neighbouring HIV-infected cells. A horizontal section shows the grey-level texture of the inside.

Fig. 2. - View showing the curvature of a human hair by pooling information on both brightness and altitude.

2.3 Human JAws. - In collaboration with the Faculty of Dentistry of Lyon, France, a complete approach $[8,9]$ for 3D image reconstruction, visualization and analysis with a final $1 \mathrm{~mm}$ resolution has been developed in the past few years, from serial X-ray images or from images acquired directly by the Morphometre ${ }^{\mathrm{TM}}$, the prototype scanner constructed by the General Electric Medical System company. This approach involved several of the previously discussed original techniques for 3D imaging [3, 4], and 3D image interpolation and visualization [10]. It also proposed a novel algorithm for image segmentation $[11,12]$. Although basically belonging to "region growing" family, this algorithm results in creating regions not necessarily connected. It has been successfully tested for dental surgery at the Odontologic Center of Lyon, France. It allows the segmentation of 3D images of jaws in significant classes (teeth, bones, cavities, sinus) (Fig. 3). It has been shown $[12,13]$ that this method performs better than classical ones.

2.4 Human EPIDERmis. - In collaboration with the L'OREAL Company, a modified tandem confocal scanning microscope was used at early 1990's to obtain in-vivo images of the human skin in real-time $[14,15]$, especially during the movement of blood cells in the capillaries. This apparatus, working with a Nipkow disk, allowed the observation of living specimens, preserving the natural state of the tissue. The focus was performed by a vertically sliding gauge piloted by a stepping motor, giving optical slices parallel to the surface of the skin with an axial and lateral resolution of about 1 micron. This TSM enabled the whole thickness of the epidermis (about 200 microns) to be acquired in less than $5 \mathrm{~s}$.

An automatic method for 3D image reconstruction and visualization has been proposed [16, 17]. It includes a Fourier-filtering-based algorithm for removing stripped pattern effect caused by the Nipkow disk and image restoration algorithms (non-linear enhancement, illumination correction...) [18]. Then, 3D measurements can be easily obtained, such as the thickness distribution of the stratum corneum (Fig. 4), or the movement of leukocytes in a capillary. 


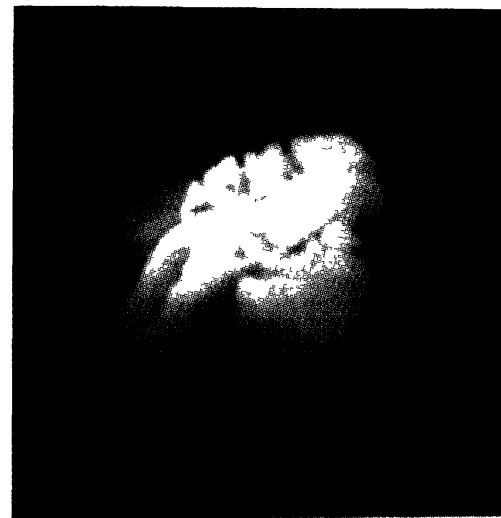

(a) sinus and nasal cavities

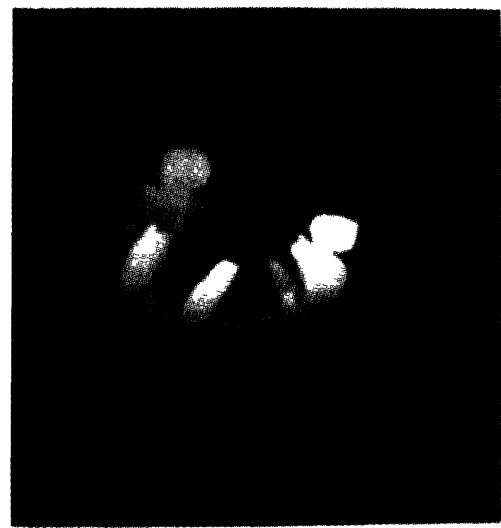

(c) reeth

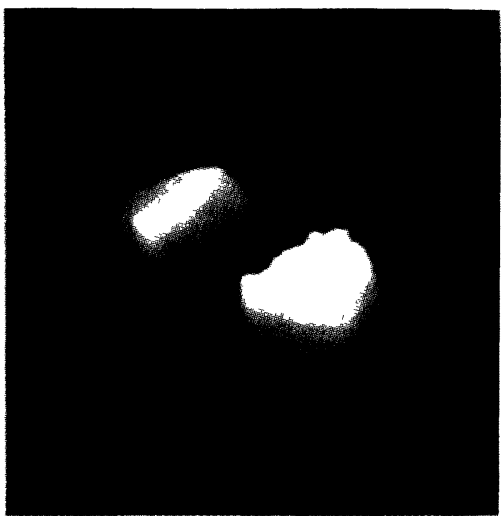

(b) sinus

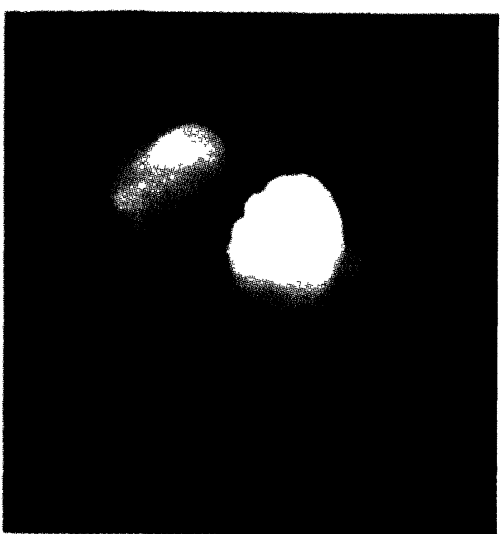

(d) teeth and sinus

Fig. 3. - View examples of three-dimensional reconstructions obtained after segmentation of different jaw elements: a) sinus and nasal cavities, b) sinus, c) teeth, d) teeth and sinus.

\section{3D Imaging Application Examples in the Materials Domain}

In early 90's, a few years later after choosing the biomedical domain for performing applied 3D image processing researches, the LISA Laboratory enlarged its 3D imaging application scope to the materials domain.

3.1 Concretes. - In collaboration with the French High School for State Public Works, Lyon, France, the problem of the 3D imaging of air bubbles in concretes was the first real situation addressed by the LISA Laboratory in the field of materials science and engineering. The calculation of the air bubbles volume included in concrete used for building barrages is essential in the understanding and control of the concrete behaviour in freezing conditions. To obtain the necessary 3D information, images of some polished concrete samples were acquired using tandem scanning confocal microscopy (TSM) and (Fig. 5). With an accurate calibration in the three axes and a curvature measurement applied to the visible pixels of each bubble, it was possible to determine the radius of the Euclidean approximating spheres and other geometrical estimators. 


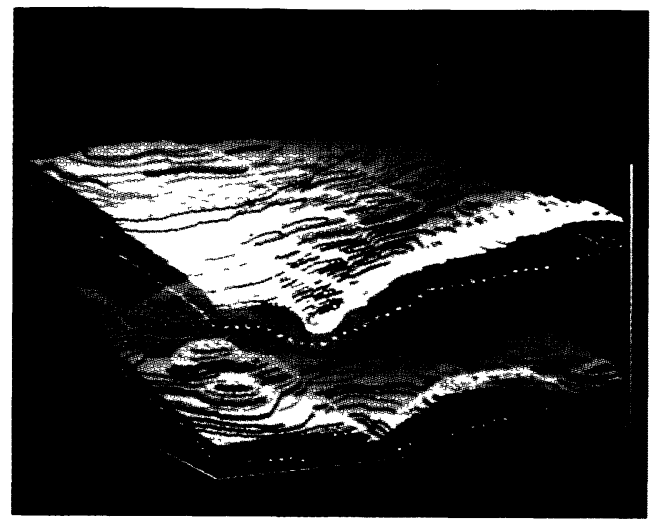

Fig. 4.

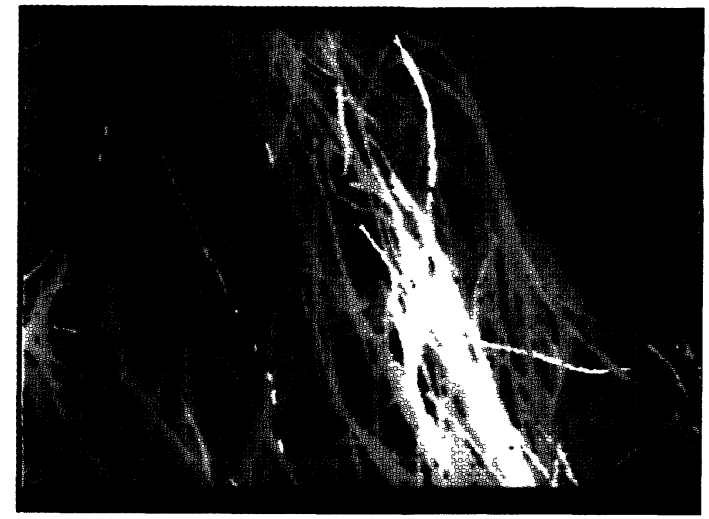

Fig. 5.

Fig. 4. - 3D imaging of the stratum corneum (upper epidermal layer): the two white surfaces represent the upper and lower limits of the stratum corneum visualized by using the $3 \mathrm{D}$ representation of the gray level images.

Fig. 5. - Topographical image of non-waved composite fibres. The gray levels represent the true altitude on the $Z$-axis.

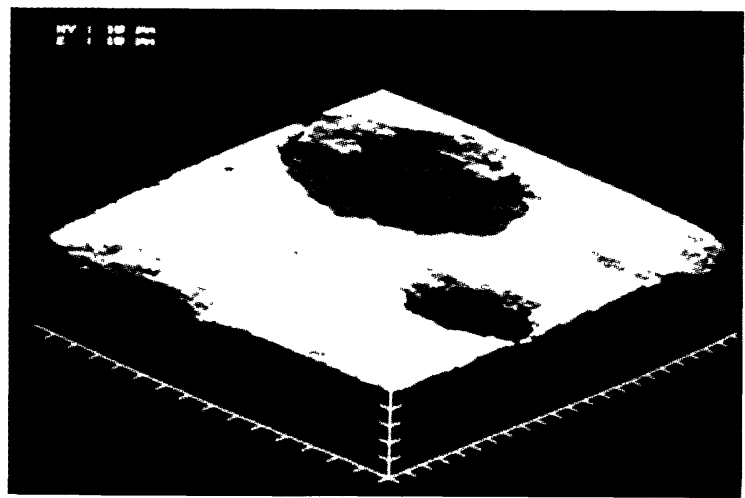

Fig. 6.

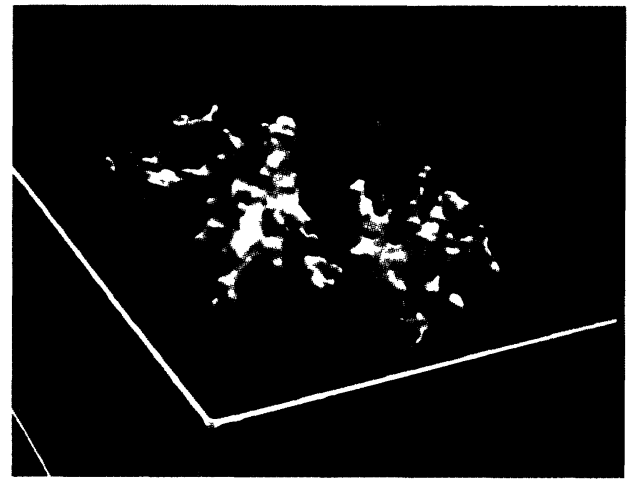

Fig. 7.

Fig. 6. - View of a concrete sample with a sectionned air bubble.

Fig. 7. - A three-dimensional view of pores in aluminium alloy. This volume is $550 \mu \mathrm{m} \times 550 \mu \mathrm{m} \times 130 \mu \mathrm{m}$ sized.

3.2 Textiles. - In collaboration with the French Textile Institute, Lyon, France, the same 3D imaging approach allowed in 1994 the quantization of the spatial distribution of fibres in a nonwaved composite material [19]. The main difficulty was the extraction of each fibre from the neighbouring ones (overlapping, crossing...). Such a problem was solved by using the 3D information, namely the altitude of each point of the fiber (Fig. 6). The results were used to characterize the thermal properties of advanced textiles. 


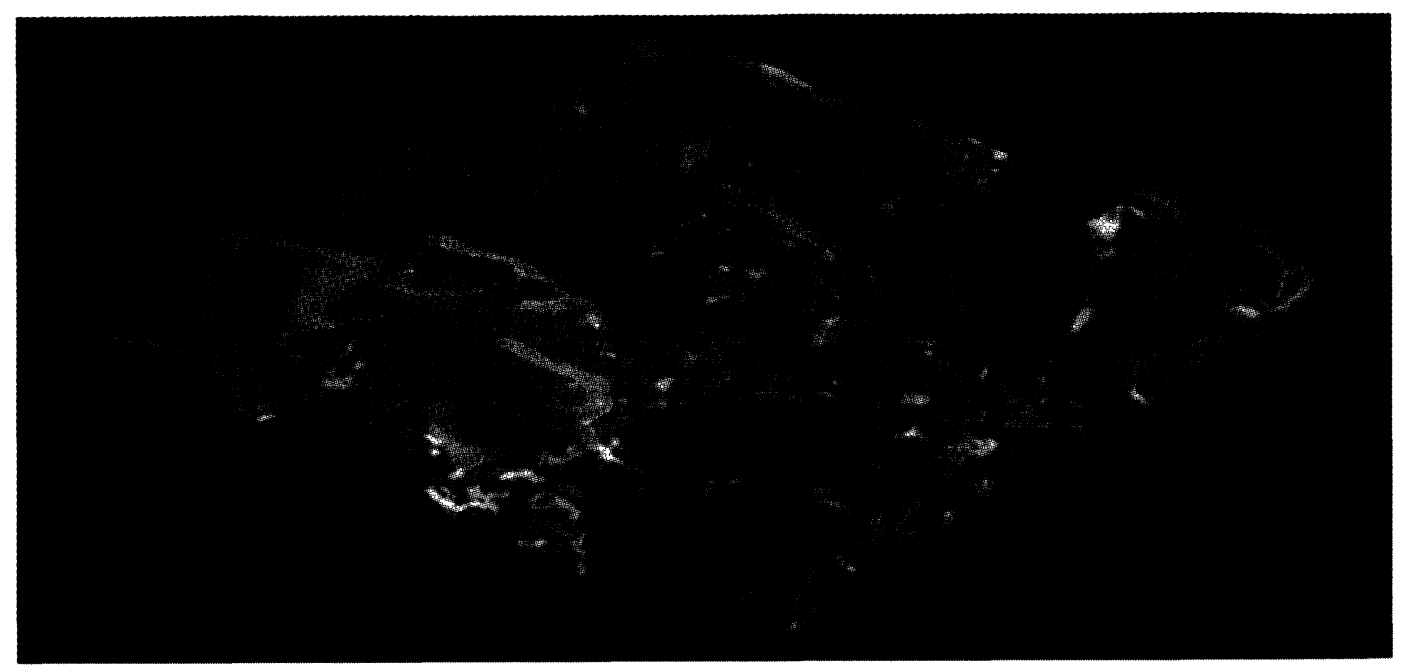

Fig. 8. - View of the high risk fallow land in orange and under cultivation zone in green in a French geographical region (research project leaded in collaboration with the Farmers association of Saône et Loire, Mâcon, France).

3.3 Aluminium Alloys. - In collaboration with the Pechiney Corporate Research Center, Voreppe, France, a dedicated method for the 3D imaging of sparsely distributed pores in aluminum alloys at a micrometric scale (resolution of $2 \mu \mathrm{m}$ ) was elaborated and reported in 1995 [20]. For volumic structural analysis of opaque metallic materials, only X-ray scanning microscopy was and is still available, but with a maximal practical resolution currently about $20 \mu \mathrm{m}$. The proposed method was based on serial cross-sectioning carried out by successive polishings and optical microscopy. A 3D image reconstruction and visualization process has also been developed [21] (Fig. 7). Geometrical and morphological algorithms can then be applied to quantify pore features [17] allowing the improvement of metallurgical models for computer simulation and the interpretation of data provided by non-destructive test systems.

\section{Conclusion}

The image processing domain truly needs to consider some constraints, e.g., the sampling phenomenon, and to take into account the physical characteristics of the images to be treated. Therefore, the mathematical operators must be powerfull, physically relevant and computationally tractable. The original and classical theories, techniques and tools involved in the above illustrated application examples not limited to the microscopical range. They may be applied in various situations, such as 3D landscape reconstruction [22] (Fig. 8).

Today, the numerous softwares dedicated to image processing and available on the market are not sufficient to cover the whole complexity of the practical problems that might be encountered. This aspect can be explained by the youth of this multidisciplinary scientific and engineering field called 3D imaging. Therefore, the creation and the carrying out of fundamental tools appear as to be more indispensable than ever before. 


\section{References}

[1] Bron C., Gremillet P., Launay D., Jourlin M., Gautschi H.P., Bächi T. and Schüpbach J., Threedimensional electron microscopy of entire cells, J. Microsc. 157 (1990) 115-126.

[2] Gremillet P., Reconstruction et visualisation de surfaces et de volumes en microscopie électronique à transmission et microscopie confocale, Thèse de Doctorat ès Sciences (University of Saint-Étienne, France, 1992).

[3] Jourlin M. and Pinoli J.C., Logarithmic image processing, Acat Stereol. 6 (1987) 651-656.

[4] Jourlin M. and Pinoli J.C., A model for logarithmic image processing, J. Microsc. 149 (1988) 21-35.

[5] Gremillet P., Jourlin M., Bron C., Schüpbach J., Gautschi H.P. and Bächi T., Dedicated image analysis techniques for three-dimensional reconstruction from serial sections in electron microscopy, Mach. Vision Applic. 4 (1991) 263-270.

[6] Gremillet P., Jourlin M. and Pinoli J.C., LIP-model-based three-dimensional reconstruction and visualization of HIV infected entire cells, J. Microsc. 174 (1995) 31-38.

[7] Corcuff P., Gremillet P., Jourlin M., Duvault Y., Leroy F. and Leveque J.L., 3D reconstruction of human hair by confocal microscopy, J. Soc. Cosmetic.Chemists 44 (1993) 1-12.

[8] Fortin T., Lair J.M., Coudert J.L., Gremilket P. and Mondou D., Intérêt de la reconstruction tridimensionnelle en odontologie, Encycl. Méd. Chir. Stomatologie-Odontologie I, 22.010.D-56, 1994.

[9] Gremillet P., Coudert J.L., Jourlin M. and Pinoli J.C., Three-dimensional image reconstruction and visualisation of human jaws, Proc. IEEE Workshop on Nonlinear Images and Signals (Halkidiki, Greece, 20-22 June 1995) pp. 819-822.

[10] Pinoli J. C., The logarithmic image processing model: Connections with human brightness perception and contrast estimators, J. Math. Imaging and Vision, accepted for publication.

[11] Revol C., Méthodes de segmentation bidimensionnelle et tridimensionnelle appliquées à l'imagerie dentaire et biomédicale, Thèse de Doctorat de l'Université de Saint-Étienne, France (November 1996).

[12] Revol C. and Jourlin M., A new minimum variance region growing algorithm for image segmentation, submitted article.

[13] Revol C., Trunde F., Coudert J L., Jourlin M. and Fortin T., Algorithme de segmentation destiné aux images odontologiques tridimensionnelles, In Proceedings $37^{\mathrm{e}}$ Congrès de la Société Francophone de Chirurgie Buccale (Paris, France, 28-29 mars 1996) in press.

[14] Corcuff P. and Lévêque J.L., In-vivo vision of the human skin with the tandem scanning microscope, Dermatology 186 (1993) 50-54.

[15] Corcuff P., Bertrand C. and Lévêque J.L., Morphometry of human epidermis by real-time confocal microscopy, Arch. Dermatol. Res. 285 (1993) 475-481.

[16] Bertrand C. and Corcuff P., In-vivo spatio-temporal visualization of the human skin by real time confocal microscopy, Scanning 16 (1994) 150-154.

[17] Bertrand C., Développement d'une nouvelle méthode d'imagerie cutanée in-vivo par microscopie confocale tandem, Thèse de Doctorat de l' University of Saint-Étienne, France (1994).

[18] Jourlin M. and Pinoli J. C., Image dynamic range enhancement and stabilization in the context of the logarithmic image processing model, Signal Process. 41 (1995) 225-237.

[19] Martinez S., Étude de la distribution tridimensionnelle de fibres composites non tissées par microscopie confocale et analyse d'image, DEA report (University of Saint-Étienne, France, 1994).

[20] Martinez S. and Pinoli J.C., 3D reconstruction, visualistaion and geometric analysis of sparsely distributed pores in aluminium alloys, International Conferences on 3D Imaging Sciences in Microscopy (Oxford, United Kingdom, 15-17 April 1996) in press.

[21] Martinez S. and Pinoli J.C., Three-dimensional image reconstruction, visualization and geometric analysis of sparsely distributed pores in aluminium alloys, submitted article.

[22] Darsonville F., Suivi dynamique de paysages, DEA report (University of Saint-Étienne, France, 1994). 